Article

\title{
New Biocompatible Mesoporous Silica/Polysaccharide Hybrid Materials as Possible Drug Delivery Systems
}

\author{
Andreea Madalina Pandele ${ }^{1}$, Corina Andronescu ${ }^{1,2}{ }^{\mathbb{D}}$, Adi Ghebaur ${ }^{1}$, Sorina Alexandra Garea ${ }^{1}$ \\ and Horia Iovu 1,3,* \\ 1 Advanced Polymer Materials Group, Faculty of Applied Chemistry and Material Science, University \\ Polytehnica of Bucharest, str. Gheorghe Polizu 1-7, 0011601 Bucharest, Romania; \\ pandele.m.a@gmail.com (A.M.P.); Corinaandronescu@yahoo.com (C.A.); ghebauradi@yahoo.com (A.G.); \\ garea_alexandra@yahoo.co.uk (S.A.G.) \\ 2 Analytical Chemistry-Center for Electrochemical Science, Ruhr-Universitat Bochum, Universitätstraße 150, \\ D-44780 Bochum, Germany \\ 3 Academy of Romanian Scientist, 0011601 Bucharest, Romania \\ * Correspondence: iovu@tsocm.pub.ro; Tel.: +4-021-402-3922
}

Received: 28 November 2018; Accepted: 19 December 2018; Published: 20 December 2018

\begin{abstract}
A high number of studies support the use of mesoporous silica nanoparticles (MSN) as carriers for drug delivery systems due to its high biocompatibility both in vitro and in vivo, its large surface area, controlled pore size and, more than this, its good excretion capacity from the body. In this work we attempt to establish the optimal encapsulation parameters of benzalkonium chloride (BZC) into MSN and further study its drug release. The influence of different parameters towards the drug loading in MSN such as $\mathrm{pH}$, contact time and temperature were considered. The adsorption mechanism of the drug has been determined by using the equilibrium data. The modification process was proved using several methods such as Fourier transform-infrared (FT-IR), ultraviolet-visible (UV-VIS), X-ray photoelectron spectroscopy (XPS) and thermogravimetric analysis (TGA). Since MSN shows a lower drug release amount due to the agglomeration tendency, in order to increase MSN dispersion and drug release amount from MSN, two common biocompatible and biodegradable polymers were used as polymer matrix in which the MSN-BZC can be dispersed. The drug release profile of the MSN-BZC and of the synthesized hybrid materials were studied both in simulated gastric fluid (SGF) and simulated intestinal fluid (SIF). Polymer-MSN-BZC hybrid materials exhibit a higher drug release percent than the pure MSN-BZC when a higher dispersion is achieved. The dispersion of MSN into the hybrid materials was pointed out in scanning electron microscope (SEM) images. The release mechanism was determined using four mathematic models including first-order, Higuchi, Korsmeyer-Peppas and Weibull.
\end{abstract}

Keywords: MSN; biopolymer; drug delivery system; in vitro kinetic studies

\section{Introduction}

In recent years, drug delivery systems have been rapidly developed and become an important field in medical applications [1,2]. Among them, oral administration is the most widely used system exhibiting many advantages including easily self-administration, painless and low cost [3].

Vallet-Regi proposed for the first time mesoporous silica nanoparticles (MSN) as controlled delivery systems [4]. Since then it was found that this type of material may be one of the greatest carrier materials for hydrophobic or hydrophilic drugs [5] due to their controlled pore size, large surface area, pore volume and, moreover, it has been demonstrated that it has very high biocompatibility 
both in vitro and in vivo [6]. Unlike other carriers, MSN exhibit a higher resistance to temperature and $\mathrm{pH}$ variation, mechanical stress and hydrolysis-induced degradations thus making a stable and rigid framework. Another important advantage of MSN for the medical field is their degradability in aqueous solution which can avoid further problems related to the removal of the material after use, being easily excreted from the body. Since for the medical field it is very important to control the pore size, geometry and shape of the carrier, in the case of MSN the size and the surface chemistry of the pore could be easily controlled and changed depending on the drug which should be encapsulated to obtain the proper loading and release of the drug. Moreover, MSN proved to exhibit a higher versatility compared with other systems like polymer nanoparticles and liposomes.

However, despite the potential benefit of this carrier for drug delivery applications, some important challenges were reported. The agglomeration tendency of the particles exhibits a strong influence on the drug-loading capacity by decreasing the amount of drug loaded due to the steric hindrance. The agglomeration tendency is specific for inorganic nanoparticles and it is a very important factor that must be taken into account [7]. Although MSN were accepted as having a low toxicity and a good biocompatibility at nano-scale, some biocompatibility studies showed that MSN particles with diameters ranging from $150 \mathrm{~nm}$ have significant toxicity at high concentrations in vitro, and cause severe systemic toxicity in vivo after intraperitoneal and intravenous injections [8]. Synthesis of hybrid materials based on biopolymers and MSN may solve some of the aforementioned problems since polymer/silica composites may encapsulate large amounts of guest molecules and subsequently release them at later stages in an optimal way [9]. Biopolymers such as chitosan (CS) and alginate (Al) exhibit many advantages for developing an ideal drug delivery system $[10,11]$. They have high biocompatibility, biodegradability, bioadhesivity, antibacterial activity, etc. So the introduction of MSN within de polymer matrices will exceed their biocompatility for the human body.

Benzalkonium chloride (BZC), a quaternary ammonium salt with the general formula $\left[\mathrm{C}_{6} \mathrm{H}_{5} \mathrm{CH}_{2} \mathrm{~N}\left(\mathrm{CH}_{3}\right)_{2} \mathrm{R}^{+}\right] \mathrm{Cl}^{-}$where $\mathrm{R}$ range from $\mathrm{C}_{8} \mathrm{H}_{17}$ to $\mathrm{C}_{19} \mathrm{H}_{39}$ is a bacteriostatic agent used as a preservative and disinfectant in the pharmaceutical industry. It is often utilized as an antiseptic and medical equipment disinfectant similar to other cationic surfactants [12,13]. It has different physical, chemical and microbiological properties.

In the present work, the optimal parameters for BZC adsorption into mesoporous silica nanoparticles and its drug release are discussed. For that, the influence of the contact time, $\mathrm{pH}$ of the solution and temperature were considered. The adsorption mechanism of the drug has been determinated by using the equilibrium data. The MSN and BZC were further incorporated into two common biopolymers and the drug release profile and the release mechanism have been also pointed out. The biopolymers were chosen in order to decrease MSN agglomeration and increase the amount of drug release. The dispersion of MSN into the two biopolymers was observed into scanning elecron microscope (SEM) images for the synthesized hybrid materials.

\section{Materials and Methods}

\subsection{Materials}

BZC, CS with medium molecular weight, Al, glutaraldehyde (GA), calcium chloride used as gelling agents and mesoporous silica (MCM-41) with a pore size of about $2.1-2.7 \mathrm{~nm}, 0.98 \mathrm{~cm}^{3} / \mathrm{g}$ pore volume and a specific surface area $\sim 1000 \mathrm{~m}^{2} / \mathrm{g}$ were purchased from Sigma Aldrich.

Sodium hydroxide, potassium phosphate monobasic, hydrochloric acid, potassium chloride were received from Sigma Aldrich.

\subsection{Immobilization of Benzalkonium Chloride (BZC) to Mesoporous Silica Nanoparticles (MSN)}

BZC was used as a model drug in order to evaluate the possible drug delivery capacity of different hybrid materials (Al-MSN; CS-MSN). 
$0.015 \mathrm{~g}$ BZC were dissolved in $2.5 \mathrm{~mL} \mathrm{pH} 5$ solutions and then $0.1 \mathrm{~g}$ of MSN were added under magnetic stirring. The stirring was maintained for $2 \mathrm{~h}$ at RT. The obtained suspension was centrifuged and dried at $35^{\circ} \mathrm{C}$ for $24 \mathrm{~h}$ in a vacuum oven.

\subsection{Synthesis of Chitosan (CS)-BZC and CS-MSN-BZC Hybrid Materials}

$50 \mathrm{mg}$ of CS powder was dissolved in $10 \mathrm{wt} . \%$ acetic acid solution for $24 \mathrm{~h}$ at RT to form a homogenous viscous solution. The CS-BZC (20 mL CS and $0.015 \mathrm{~g}$ BZC) and CS-MSN-BZC (20 mL CS solution, $0.015 \mathrm{~g}$ BZC and $0.1 \mathrm{~g}$ MSN) suspension were obtained by mixing the two or three compounds and mechanically stirring at room temperature (RT) for $2 \mathrm{~h}$. Then $0.0225 \mathrm{~mL}$ aqueous solution of GA (25 wt.\%) was added as crosslinking agent and the stirring was continued for another one hour. CS-BZC and CS-MSN-BZC hybrid materials were cast onto transparent Petri dish and left undisturbed for $72 \mathrm{~h}$ at RT for solvent evaporation and thus, allowing to form thin films.

\subsection{Synthesis of Alginate (Al)-BZC and Al-MSN-BZC Hybrid Materials}

A solution of $\mathrm{Al}$ was prepared by dissolving $50 \mathrm{mg}$ of $\mathrm{Al}$ in $50 \mathrm{~mL}$ of water for $3 \mathrm{~h}$. The $\mathrm{Al}-\mathrm{BZC}$ and Al-MSN-BZC suspensions were obtained following the same procedure described above (see Section 2.3). After solvent evaporation, the films were peeled off from the mold and impregnated in $1 \% \mathrm{CaCl}_{2}$ aqueous solution for $1 \mathrm{~h}$. The samples were washed several times with water to remove $\mathrm{CaCl}_{2}$ excess and dried for $24 \mathrm{~h}$ at $\mathrm{RT}$.

\subsection{Characterization}

Fourier transform-infrared (FT-IR) measurements were performed on a Bruker VERTEX 70 spectrometer. The FT-IR spectra were recorded in $400 \div 4000 \mathrm{~cm}^{-1}$ range with $4 \mathrm{~cm}^{-1}$ resolution. The samples were analyzed from $\mathrm{KBr}$ pellets.

The X-ray photoelectron spectroscopy (XPS) spectra were registered on a Thermo Scientific K-Alpha equipment, fully integrated, with an aluminum anode monochromatic source. Charging effects were compensated by a flood gun. Pass energy of $200 \mathrm{eV}$ and $20 \mathrm{eV}$ were used for surgery and high resolution spectra aquisition respectively.

Thermogravimetric analysis (TGA) was done on a Q500 TA Instruments equipment. $2 \mathrm{mg}$ of sample was heated from RT to $700{ }^{\circ} \mathrm{C}$ using a heating rate of $10{ }^{\circ} \mathrm{C} / \mathrm{min}$ under constant nitrogen flow rate.

UV adsorption measurements of BZC were performedat $\lambda=262 \mathrm{~nm}$ on a UV 3600 Shimadzu equipment provided with aquartz cell having a light path of $10 \mathrm{~mm}$.

The morphological characterization of the CS/Al-MSN-BZC composite films was evaluated from the micrograph recorded using a Philips X1 30 ESEM TMP scanning electron microscope (SEM).

\subsection{Adsorption Experiments}

For adsorption experiments, the influences of contact time, temperature, concentration of the drug and buffer $\mathrm{pH}$ were investigated. To establish the influence of contact time on the BZC adsorption on MSN, $0.015 \mathrm{~g}$ BZC and 0.1 g MSN were mixed in various buffer solutions with $\mathrm{pH} 5$ for 10, 30, 60, 120, 240, $360 \mathrm{~min}$. The influence of the temperature reaction was studied using the same quantities of drug and MSN. The reactions were kept for $1 \mathrm{~h}$, at room temperature, $40^{\circ} \mathrm{C}, 60^{\circ} \mathrm{C}$ and $80^{\circ} \mathrm{C}$. The effect of $\mathrm{pH}$ was studied by maintaining the temperature reaction for $1 \mathrm{~h}$ at $80^{\circ} \mathrm{C}$ in solutions with different $\mathrm{pH}$ values: $3,4,5,6,7,8,9,10,11$. Another important parameter that was studied was the initial drug concentration: 3 g/L, 6 g/L, 11 g/L, 18 g/L, 24 g/L, 36 g/L, 47 g/L, 100 g/L, 200 g/L.

The unabsorbed drug concentration was determined from ultraviolet (UV) spectra at $262 \mathrm{~nm}$, after the centrifugation of MSN-BZC suspension. The amounts of drug adsorbed at time $\mathrm{t}\left(Q_{t}, \mathrm{mg} / \mathrm{g}\right)$ and at equilibrium $\left(Q_{e}, \mathrm{mg} / \mathrm{g}\right)$ were calculated using the following equations: 


$$
\begin{aligned}
& Q_{t}=\frac{\left(C_{0}-C_{t}\right) V}{W} \\
& Q_{e}=\frac{\left(C_{0}-C_{e}\right) V}{W}
\end{aligned}
$$

where $C_{0}, C_{t}, C_{e}(\mathrm{mg} / \mathrm{L})$ are the initial, the time and the equilibrium concentrations of BZC solution; $V(\mathrm{~L})$ is the volume of BZC solution, $W(\mathrm{~g})$ is the mass of MSN employed

\subsection{In Vitro Drug Release Studies}

The drug release studies were accomplished into a fully automated dissolution bath USP Apparatus 1 (708-DS Agilent) connected to an autocontrolled multi-channel peristaltic pump (810 Agilent) and at a UV-VIS spectrophotometer (Cary 60) with $1 \mathrm{~mm}$ flow cell and UV-Dissolution software. In a dialysis membrane bag was introduced certain amount of BZC-MSN, CS/Al-BZC and CS/AL-MSN-BZC hybrid materials and $4 \mathrm{~mL}$ buffer solution of $\mathrm{pH} 7.4$ (simulated intestinal fluid, SIF) and pH 1.2 (simulated gastric fluid, SGF) respectively prepared as described by A. Ghebaur and coworkers [14]. These dialysis membranes were caught by the Apparatus 1 rods and immersed in $200 \mathrm{~mL}$ buffer solution.

The dissolution bath temperature was kept constant at $37^{\circ} \mathrm{C}$ and the spindle rotation speed was set $100 \mathrm{rpm}$. At various time intervals the dissolution media were automatically extracted and the BZC concentration was calculated from the UV adsorption at $262 \mathrm{~nm}$.

\subsection{In Vitro Kinetic Evaluation}

In vitro kinetic evaluation of BZC from different types of materials was analyzed by 4 various kinetic models: first order, Higuchi, Kormeyer-Peppas, Weibull.

First order model describes the release of drug from pharmaceutical forms that encapsulate water-soluble drugs in porous matrices [15] according to this model

$$
\log C=\log C_{0}-\frac{K t}{2.303}
$$

where $C_{0}$ is the initial concentration of drug, $K$ is the first order rate constant and $t$ is the time. The obtained data are plotted as log cumulative percent of drug remaining vs. time. A straight line with the slope $-K / 2.303$ will be obtained.

Higuchi model descries the release of water soluble and low soluble drugs from semisolid and/or solid matrices [16,17].

The equations that describes the Higuchi model is:

$$
\mathrm{Q}=K_{H} \times t^{1 / 2}
$$

where $\mathrm{Q}$ is the amount of drug release at time $t, K_{H}$ is the Higuchi dissolution constant. The data obtained are plotted as cumulative percentage drug release versus square root of time.

Korsmeyer-Peppas model describes the release of a drug from a polymeric system [18-20].

The equation for this model is:

$$
\frac{M_{t}}{M_{\infty}}=k t^{n}
$$

where $M_{t} / M_{\infty}$ is fraction of drug released at time $t, k\left(\mathrm{~min}^{-n}\right)$ is the release rate constant and $n$ is the release exponent. The data obtained are plotted as log cumulative percentage drug release versus log time. The $n$ value is used to determine the release mechanism (see Table 1). 
Table 1. Interpretation of drug transport mechanism for film-like materials.

\begin{tabular}{cc}
\hline $\mathrm{n}$ & Transport mechanism \\
0.5 & Fickian diffusion \\
$0.5<\mathrm{n}<1$ & Anomalous Transport \\
1 & Case II transport \\
$1<\mathrm{n}$ & Super case II transport \\
\hline
\end{tabular}

The Weibull model is use to compare the release profile of different types of drug delivery matrixes [21]. The equation that describes this model is:

$$
\frac{M_{t}}{M_{\infty}}=1-\exp \left(-a t^{b}\right)
$$

where $M_{t}$ is accumulated fraction of drug in solution at time $t, M_{\infty}$ is total amount of drug being released, $a$ is the scale parameter that defines the time scale process, $b$ is the parameter that describes the shape of the dissolution curve progression. For $b=1$ the curve shape is exponential, $b>1$ the curve shape is sigmoidal and if $b<1$ the curve shape is parabolic.

\section{Results and Discussion}

\subsection{Characterization of the Modified MSN with BZC}

FT-IR analysis

The FT-IR spectra were recorded to confirm the interaction between MSN and BZC (see Figure 1). The MSN spectrum exhibits the bands at $453 \mathrm{~cm}^{-1}, 861 \mathrm{~cm}^{-1}, 1087 \mathrm{~cm}^{-1}$ and $1643 \mathrm{~cm}^{-1}$ assigned to the characteristic vibrations of the silica substrate [22]. The band at $1643 \mathrm{~cm}^{-1}$ can be attributed to the adsorbed water molecules while the bands at $453 \mathrm{~cm}^{-1}, 861 \mathrm{~cm}^{-1}, 1087 \mathrm{~cm}^{-1}$ were assigned to Si-O-Si bending and stretching vibrations. From the FT-IR spectrum of modified MSN with BZC some additional peak can be observed which confirm the presence of BZC. Thus the bands from $2966 \mathrm{~cm}^{-1}$, $2928 \mathrm{~cm}^{-1}$ and $2858 \mathrm{~cm}^{-1}$ are attributed to symmetric and asymmetric stretching vibration of the $\mathrm{C}-\mathrm{H}$ bond of the BZC tail. The peak from $701 \mathrm{~cm}^{-1}$ corresponds to the $\mathrm{C}-\mathrm{H}$ bending vibration from aromatic ring while the $1458 \mathrm{~cm}^{-1}$ and $1488 \mathrm{~cm}^{-1}$ peaks are assigned to the $\mathrm{C}-\mathrm{H}$ bending from methyl $\left(-\mathrm{CH}_{3}\right)$ and methylene $\left(-\mathrm{CH}_{2}\right)$ groups [12].

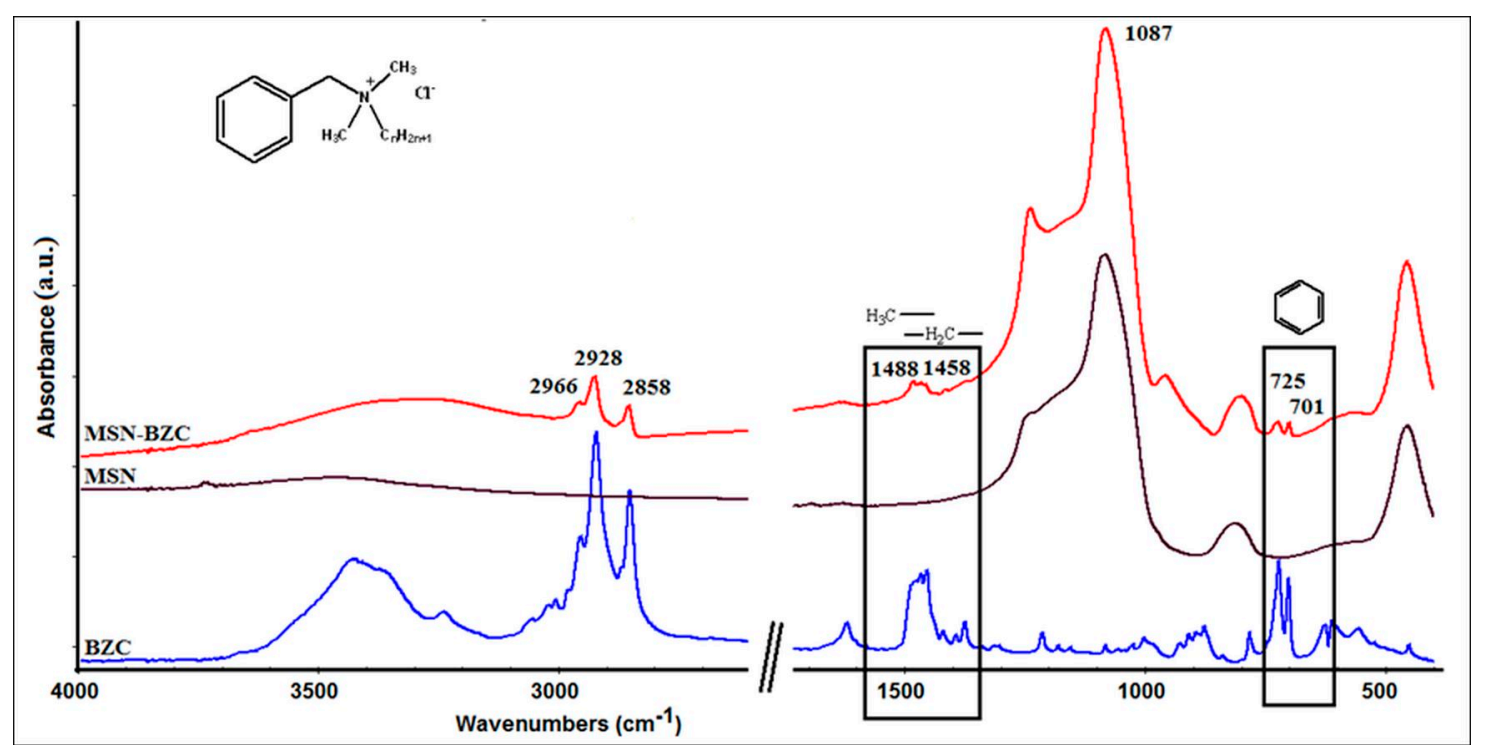

Figure 1. The Fourier transform-infrared (FT-IR) spectra for mesoporous silica nanoparticles (MSN), benzalkonium chloride (BZC) and MSN modified with BZC. 


\section{XPS analysis}

The XPS analysis of MSN modified with BZC was done to show the chemical composition of the surface after the modification process (Figure 2). All the samples show the Si 2p and O 1s peaks which are assigned to silica framework. In the XPS survey spectra of the modified MSN, the presence of $\mathrm{C} 1 \mathrm{~s}(\mathrm{BE}=282 \mathrm{eV})$ and $\mathrm{N} 1 \mathrm{~s}(\mathrm{BE}=402 \mathrm{eV})$ can be clearly observed indicating that the modification process occurred.

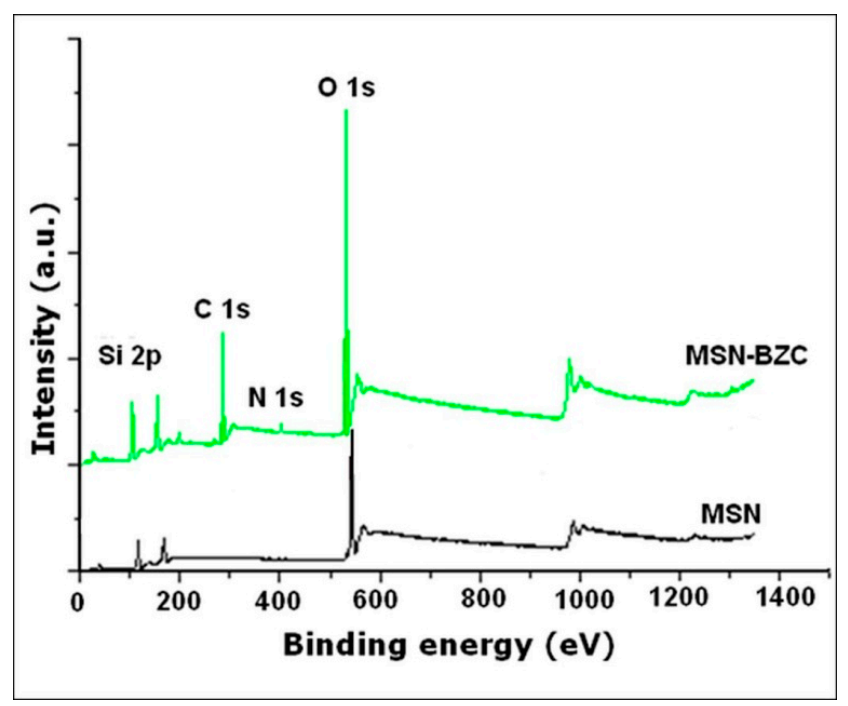

Figure 2. The X-ray photoelectron spectroscopy (XPS) survey spectra for MSN and modified MSN with BZC.

\section{TGA data}

The adsorption of BZC onto MSN was also confirmed from TGA curves (Figure 3). The MSN modified with BZC shows two thermal decomposition steps. The first step, around $200^{\circ} \mathrm{C}$, is attributed to the thermal degradation of the loaded drug and the second step which occurs at a higher temperature, around $300{ }^{\circ} \mathrm{C}$, is assigned to the thermal degradation of the inorganic fraction [23].

The MSN modified with BZC exhibits also an increase of weight loss compared to unmodified MSN which is due to the thermal degradation of the organic compound adsorbed onto the MSN surface or/and within MSN pores.

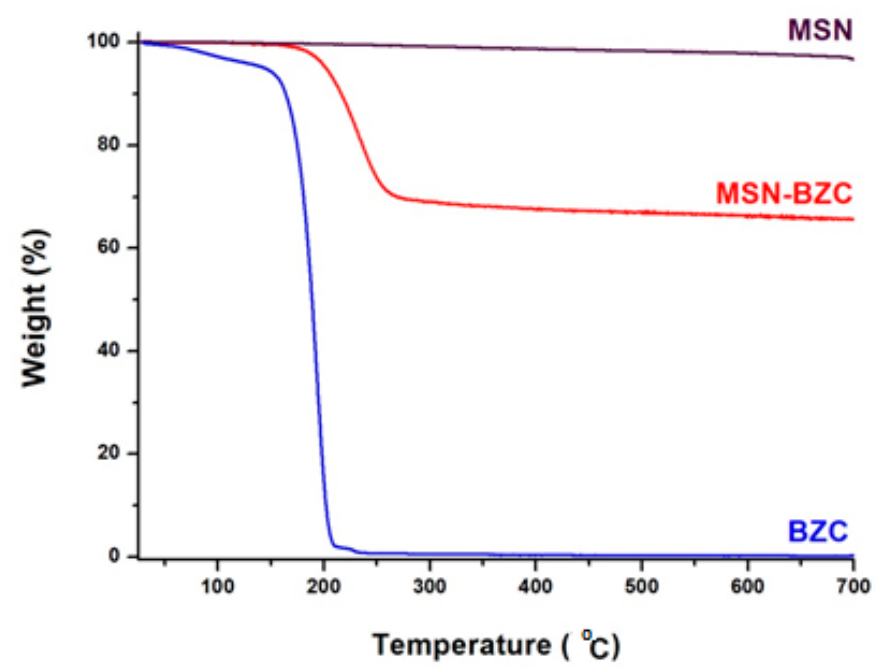

Figure 3. Thermogravimetric analysis (TGA) curves for MSN, BZC and MSN modified with BZC. 


\subsection{The Influence of Contact Time, $p H$, Temperature and Concentration of BZC}

Contact time influence

The effect of the contact time for the adsorption of BZC onto MSN is presented in Figure 4. MSN has a good adsorption capacity, within $60 \mathrm{~min}$ the equilibrium being achieved. There was no significant change between the samples from $1 \mathrm{~h}$ to $6 \mathrm{~h}$.

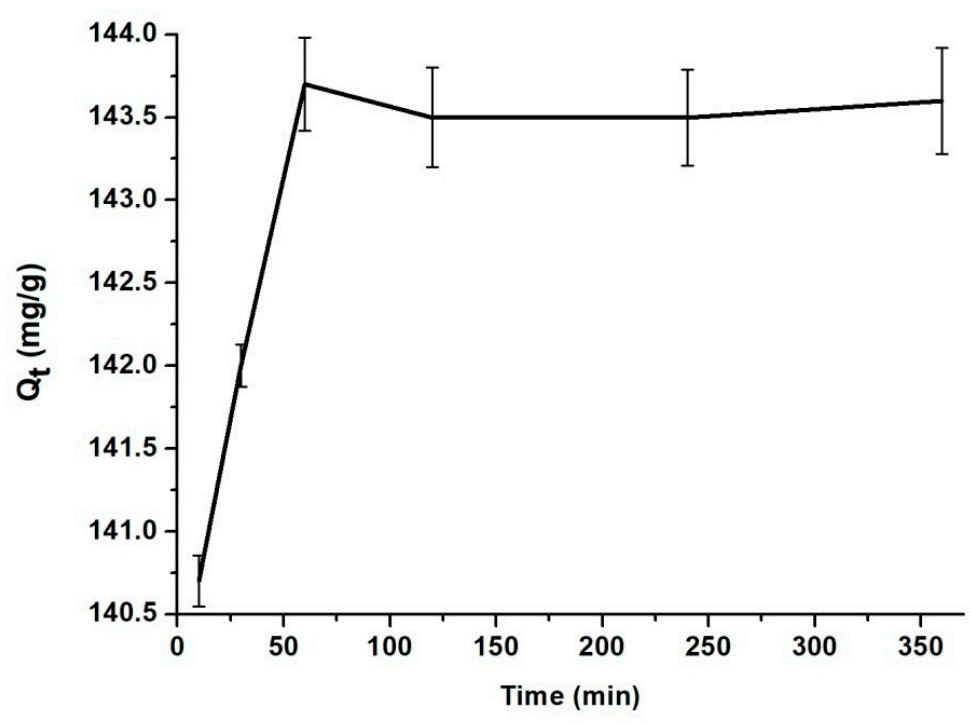

Figure 4. The influence of the contact time of BZC with MSN.

In order to determine the adsorption process type and to predict the adsorption rate, the kinetic parameters were determined. The adsorption of BZC onto MSN has been calculated using the pseudo-second order equation:

$$
\frac{d q_{t}}{d_{t}}=k_{2}\left(q_{e}-q_{t}\right)^{2}
$$

where $k_{2}$ is the rate constant of second-order adsorption in $\left(\mathrm{g} \mathrm{mg}^{-1} \mathrm{~min}^{-1}\right)$.

Equation (7) can be integrated using boundary conditions $t=0$ to $t=\mathrm{t}$ and $q=0$ to $q=\mathrm{q}$ and gives:

$$
\frac{1}{\left(q_{e}-q\right)}=\frac{1}{q_{e}}+k_{2} t
$$

Equation (8) can be linear, written as:

$$
\frac{t}{\left(q_{t}\right)}=\frac{1}{k_{2} \times q_{e}^{2}}+\frac{1}{q_{e}} t
$$

The straight-line plots of $(t / q)$ versus $t$ have been drawn to obtain rate parameters, $k_{2}$ and $q_{e}$ [24].

The high correlation coefficient $\left(\mathrm{R}^{2}=1\right)$ suggests that the adsorption process of BZC onto MSN follows the pseudo-second-order kinetic model (see Table 2). Also, the calculated $q_{e}$ has almost the same value as the $q_{e}$ determined experimental [25].

Table 2. Kinetic parameters for BZC adsorption onto MSN.

\begin{tabular}{cc}
\hline \multicolumn{2}{c}{ Kinetic Model } \\
\hline \multicolumn{2}{c}{ Pseudo-Second Order } \\
\hline$q_{e}$, calc $(\mathrm{mg} / \mathrm{g})$ & 142.85 \\
$k_{2}(\mathrm{~g} / \mathrm{mg}$ min $)$ & 0.037692 \\
$\mathrm{R} 2$ & 1 \\
\hline
\end{tabular}


Table 2. Cont.

\begin{tabular}{cc}
\hline \multicolumn{2}{c}{ Kinetic Model } \\
\hline \multicolumn{2}{c}{ Intr-Particle Diffusion } \\
\hline $\mathrm{k}_{\mathrm{p}}(\mathrm{mg} / \mathrm{g}$ min $)$ & 0.6245 \\
$\mathrm{R} 2$ & 0.9914 \\
\hline
\end{tabular}

The temperature influence

The temperature effect on drug adsorption onto MSN was studied at RT, $40{ }^{\circ} \mathrm{C}, 60^{\circ} \mathrm{C}$ and $80^{\circ} \mathrm{C}$. As can be observed in Figure 5, the highest amount of drug, $144.9 \mathrm{mg} / \mathrm{g}$, was adsorbed at RT. At higher temperature values BZC starts too degraded, according to TG analysis (Figure 3).

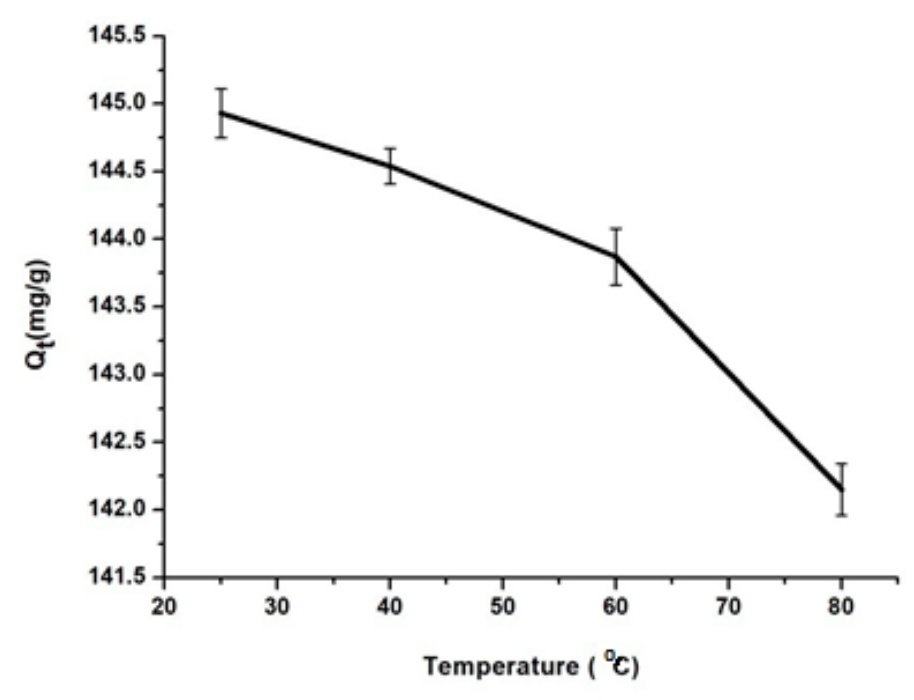

Figure 5. Adsorption of BZC at different temperature onto MSN.

Also, the thermodynamic parameters were calculated. The free energy $\left(\Delta \mathrm{G}^{0}\right)$, enthalpy $\left(\Delta \mathrm{H}^{0}\right)$ and entropy $\left(\Delta S^{0}\right)$ were calculated using the following equations:

$$
\begin{gathered}
\Delta \mathrm{G}^{0}=-\mathrm{RT} \ln (\mathrm{Kc}) \\
\Delta \mathrm{G}^{0}=\Delta \mathrm{H}^{0}-\mathrm{T} \Delta \mathrm{S}^{0} \\
\mathrm{Kc}=\mathrm{Q} e / \mathrm{Ce}
\end{gathered}
$$

where $\mathrm{Kc}(\mathrm{L} / \mathrm{g})$ is the adsorbed capacity to retain the active substance, $\mathrm{R}(8.314 \mathrm{~J} / \mathrm{mol} \mathrm{K})$ is the universal gas constant and $\mathrm{T}(\mathrm{K})$ is the temperature. The values of $\Delta \mathrm{H}^{0}$ and $\Delta \mathrm{S}^{0}$ are calculated from the slope and intercept of the plot of $\ln (\mathrm{Kc})$ versus $1 / \mathrm{T}$ (Table 3). The negative values of the free energy indicate a spontaneous and physical process. This is confirmed by $\Delta \mathrm{H}^{0}$ values, which are smaller than $25 \mathrm{~kJ} / \mathrm{mol}$ [26]. The positive values of $\Delta S^{0}$ indicate a higher disorder of MSN as the adsorbed drug onto their surface increase. Since $\Delta G^{0}$ is negative and $\Delta S^{0}$ positive, the adsorption process is spontaneous with high affinity for BZC [27].

Table 3. Thermodynamic parameters for BZC adsorption onto MSN.

\begin{tabular}{ccccc}
\hline Temperature (K) & 298 & 313 & 333 & 353 \\
\hline$\Delta G^{0}(\mathrm{~kJ} / \mathrm{mol})$ & -2.3 & -2.77 & -3.4 & -4.02 \\
$\Delta \mathrm{H}^{0}(\mathrm{~kJ} / \mathrm{mol})$ & \multicolumn{4}{c}{7.04} \\
$\Delta \mathrm{S}^{0}(\mathrm{~kJ} / \mathrm{molK})$ & \multicolumn{5}{c}{0.031} \\
\hline
\end{tabular}


The $\mathrm{pH}$ influence

The $\mathrm{pH}$ value of the solution is one of the most important parameters for the adsorption of pharmaceutics onto mesoporous silica nanoparticles surface or pores. Solutions with the $\mathrm{pH}$ values in the range between 3 to 11 were employed, these values being adjusted with $\mathrm{HCl} 0.1 \mathrm{~N}$ or $\mathrm{NaOH}$ $0.1 \mathrm{~N}$ solutions.

The $\mathrm{pH}$ influence on the adsorption process of BZC onto the MSN surface or pores is shown in Figure 6. Thus, a BZC solution with an initial concentration of $6 \mathrm{~g} / \mathrm{L}$ was used. Up to $\mathrm{pH} 5$, the amount of the adsorbed BZC increases. After, a slowly decreases is observed to $\mathrm{pH} 6$ and furthermore an abrupt decreases at higher $\mathrm{pH}$ values was noticed [28]. This phenomenon takes place because, at this concentration, the $\mathrm{pH}$ solution is $5-6$ and the drug solubility is maximum [29]. Also, the molecule activity in solvent at this concentration and $\mathrm{pH}$ value is maximum.

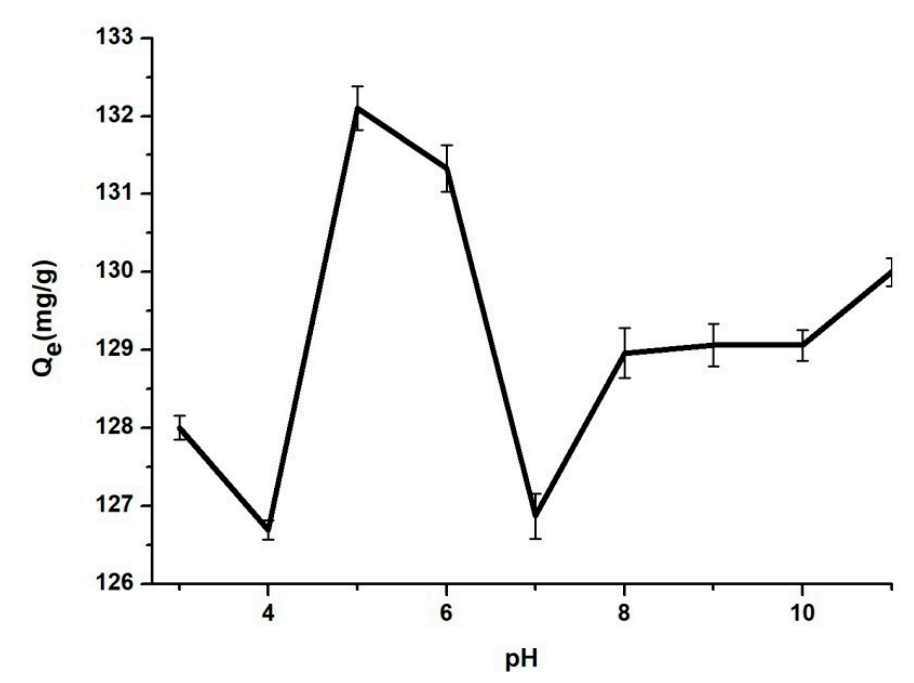

Figure 6. Adsorption of BZC at different $\mathrm{pH}$ values onto MSN.

The influence of initial drug concentration

Figure 7 illustrates the effect of initial BZC concentration against adsorption onto MSN. An increase of the equilibrium values from 18.56 to $352 \mathrm{mg} / \mathrm{g}$ for the adsorbed amount of the drug onto MSN was noticed when the initial drug concentration was increased from 3000 to $50,000 \mathrm{mg} / \mathrm{L}$. For values of $C_{0}$ higher than $50,000 \mathrm{mg} / \mathrm{L}$, the values of $\mathrm{q}_{\mathrm{e}}$ are almost unchanged.

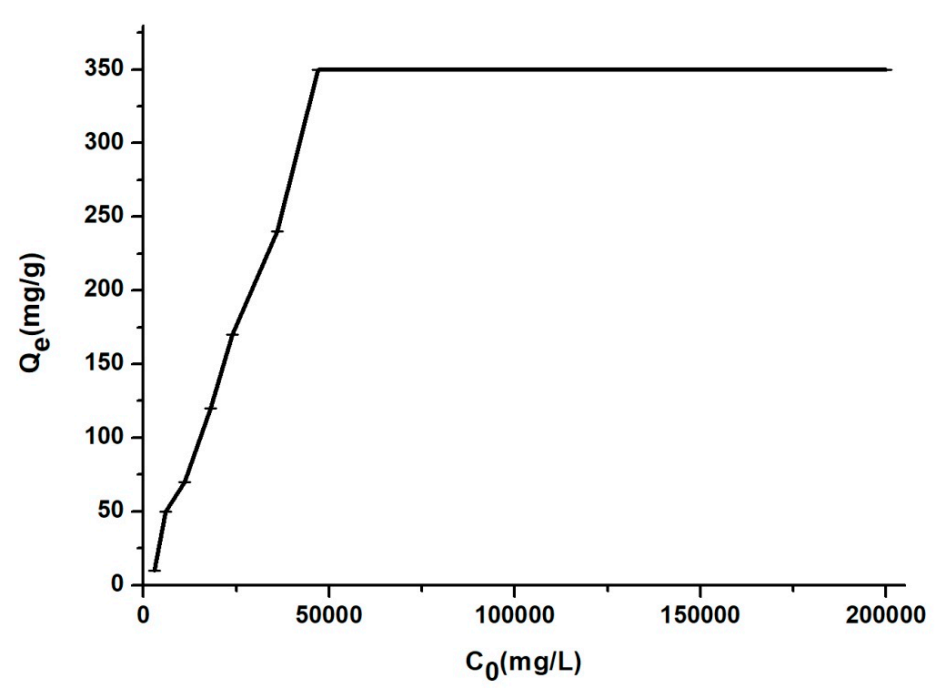

Figure 7. The influence of drug concentration onto MSN. 


\subsection{In Vitro Release Studies}

In vitro release of BZC was investigated both in SIF (pH 7.4) and SGF (pH 1.2). Figures 8 and 9 show the amount of BZC released from MSN, from the two biopolymers and from the corresponding hybrid systems. At pH 1.2 (Figure 8), the systems CS-BZC and CS-MSN-BZC release a higher amount of drug than Al-BZC and Al-MSN-BZC systems due to the high swelling degree of CS in SIF [30]. At $\mathrm{pH}$ 7.4, the amount of the drug released within $24 \mathrm{~h}$ from the CS was higher than for $\mathrm{Al}$ also due to the good swelling behavior of the biopolymer in SIF which favors the diffusion of the drug molecules. Conversely, the lower release amount of BZC from Al matrix was attributed to a higher crosslinking density of the polymer which slows down considerably the diffusion of the drug and inhibits the crossing of water molecules through the polymer chains. These results are in good agreement with Xiujuan Huang and coworkers who report that the delivery of the drug might be determinate by varying the amount of sodium alginate and $\mathrm{CaCl}_{2}$ concentration [30]. Moreover, Figures 8 and 9 show that the amount of BZC released from MSN-BZC systems is lower than the amount of drug released from the CS-MSN-BZC and Al-MSN-BZC hybrid materials. These results were attributed to a good dispersion of MSN in polymer matrices which reduced nanoparticles agglomeration and enabled a better drug diffusion.

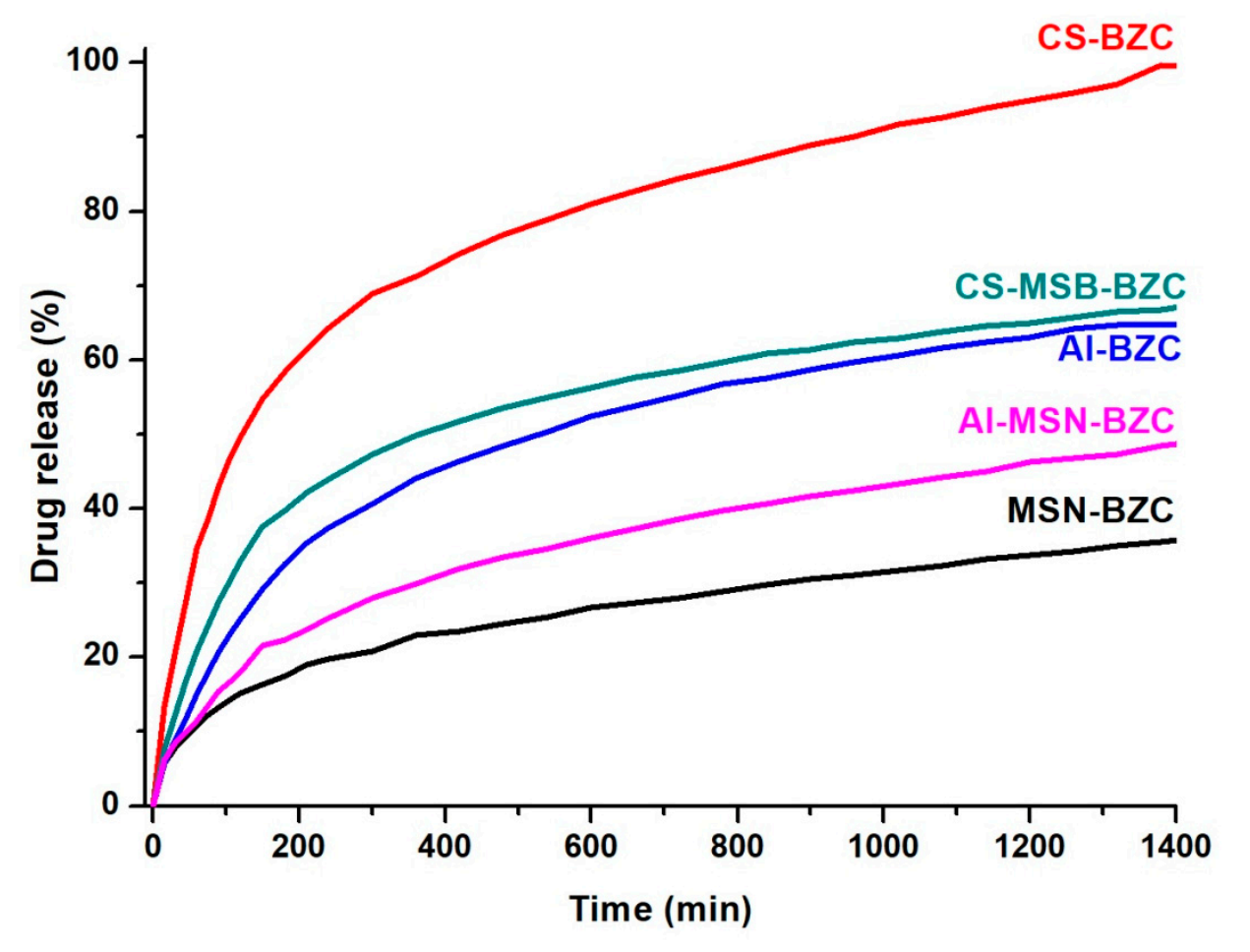

Figure 8. The release profile of BZC from different hybrid materials in simulated gastric fluid (SGF). 


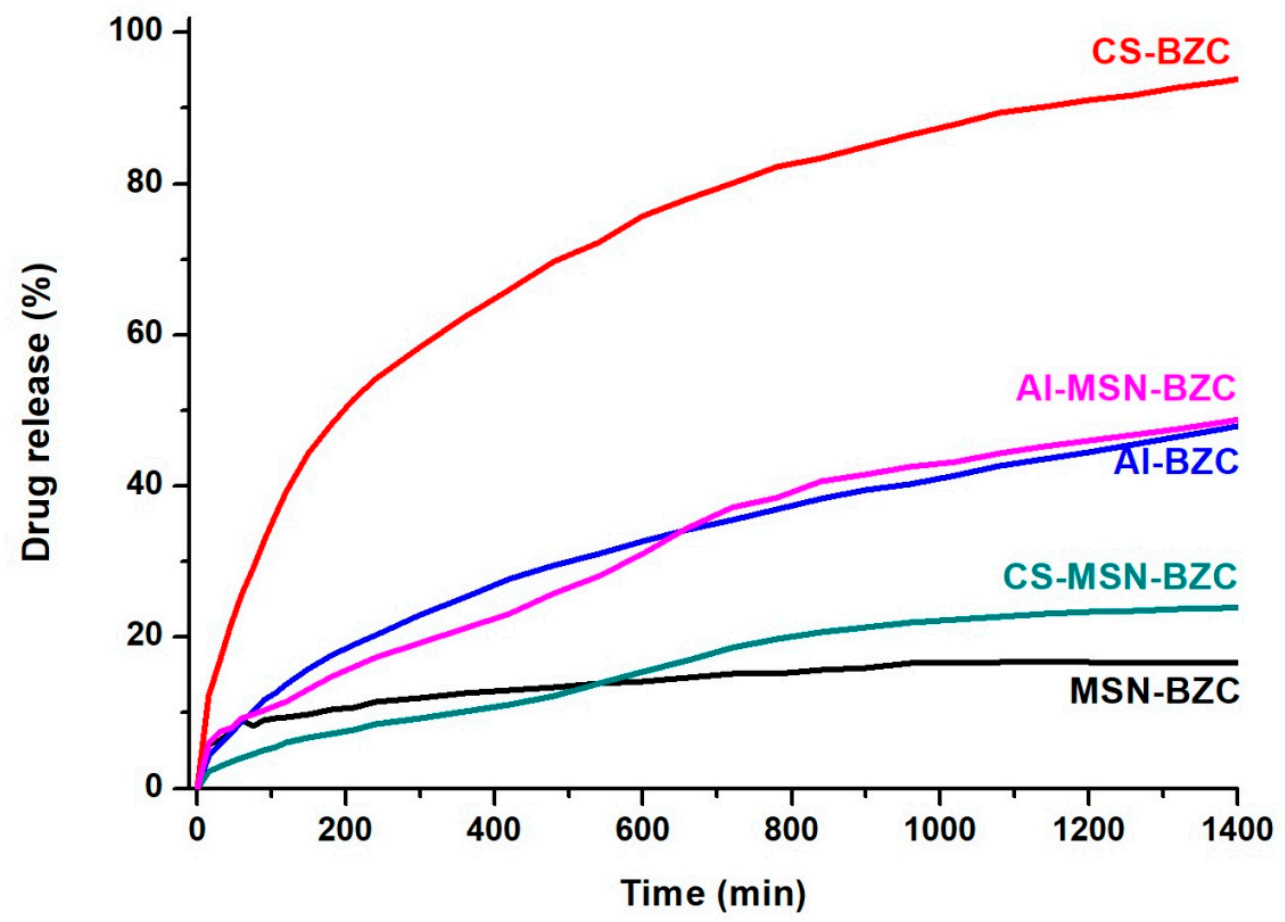

Figure 9. The release profile of BZC from different hybrid materials in simulated intestinal fluid (SIF).

\subsection{Scanning Electron Microscopy (SEM) Analysis}

In order to prevent the already reported agglomeration and sedimentation of MSN into aqueous solution [31], MSN was dispersed into the polymer matrix to achieve a more stable colloidal system. The dispersion of MSN into the polymer matrix was investigated by SEM. Figure 10 displays the surface morphology of both CS-MSN-BZC and Al-MSN-BZC films. According to the micrographs, the MSN dispersion in CS and $\mathrm{Al}$ is different. While a good dispersion is observed for Al-MSN-BZC, in the case of CS-MSN-BZC agglomerates are noticed. This result supports our initial claim, that a better MSN-BZC dispersion will facilitate the drug release and explains the higher drug release percent registered for Al-MSN-BZC in comparison with the CS-MSN-BZC hybrid material.

\section{CS-MSN-BZC}

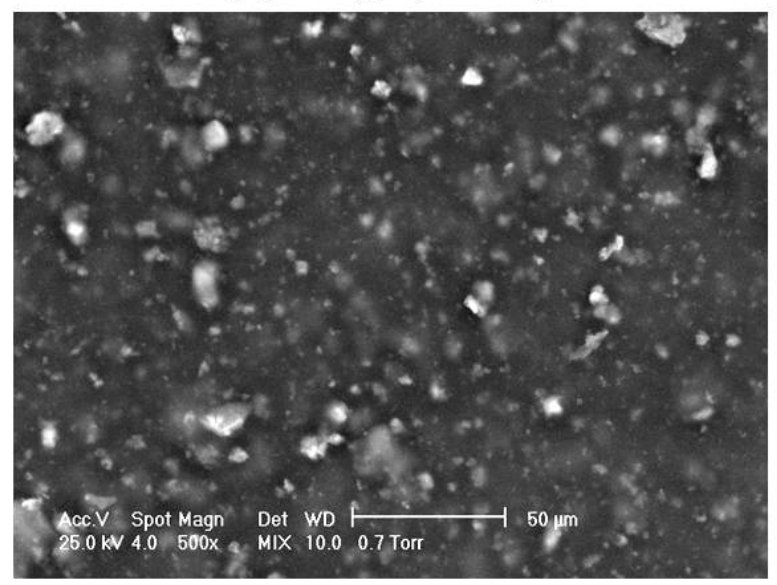

Al-MSN-BZC

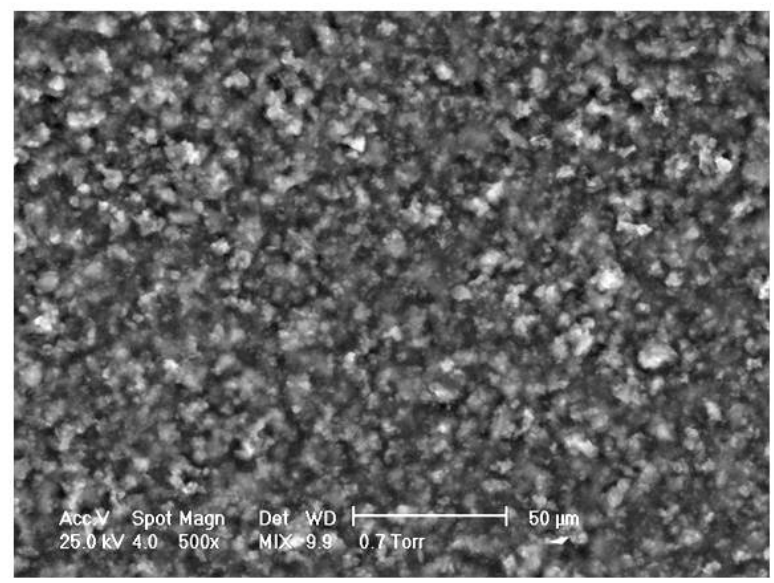

Figure 10. Scanning electron microscope (SEM) images recorded on the CS-MSN-BZC and AL-MSN BZC films. 


\subsection{In Vitro Kinetic Evaluation}

The release mechanism of drug from different type of materials depends by the physic-chemical properties of host materials and the pore size from the materials or by the size of microparticles or nanoparticles [32]. Four types of mathematic models were used in this paper to determine the release mechanism of BZC from MSN-BZC, AL-BZC, CS-BZC, AL-MSN-BZC and CS-MSN-BZC in two different release media ( $\mathrm{pH} 1.2$ and $\mathrm{pH}$ 7.4). The calculated parameters from these models are presented in Table 4. The mathematic model which shows a correlation coefficient (R) near 1 is the model that is suitable to characterize the release mechanism.

Table 4. Kinetic release parameters of BZC release process from MSN-BZC, AL-BZC, CS-BZC, AL-MSN-BZC, CS-MSN-BZC in different simulated body fluids.

\begin{tabular}{|c|c|c|c|c|c|c|c|c|c|c|c|c|}
\hline \multirow{2}{*}{\multicolumn{2}{|c|}{ Sample }} & \multicolumn{3}{|c|}{ First Order } & \multicolumn{2}{|c|}{ Higuchi } & \multicolumn{3}{|c|}{ Korsmayer-Peppas } & \multicolumn{3}{|c|}{ Weibull } \\
\hline & & \multirow{3}{*}{$\begin{array}{c}\begin{array}{c}\mathrm{C}_{\mathbf{0}}, \\
\mathbf{m g} / \mathrm{g}\end{array} \\
94.8 \\
93.22\end{array}$} & \multirow{3}{*}{$\begin{array}{c}\mathbf{K}, \mathbf{h}^{-\mathbf{1}} \\
0.00069 \\
1.15 \times 10^{-6}\end{array}$} & \multirow{3}{*}{$\begin{array}{c}\mathbf{R}^{2} \\
0.89652 \\
0.9007\end{array}$} & \multirow{3}{*}{$\begin{array}{c}\begin{array}{c}\mathbf{K}_{\mathbf{H}} \\
\mathbf{h}^{-\mathbf{1 / 2}}\end{array} \\
0.138 \\
0.093\end{array}$} & \multirow{3}{*}{$\begin{array}{c}\mathbf{R}^{2} \\
0.9339 \\
0.8327\end{array}$} & \multirow{3}{*}{$\begin{array}{c}\begin{array}{c}\mathbf{K} \\
\left(\mathrm{min}^{-\mathbf{n}}\right)\end{array} \\
0.4428 \\
0.4203\end{array}$} & \multirow{3}{*}{$\begin{array}{c}\mathbf{n} \\
0.3848 \\
0.2916\end{array}$} & \multirow{3}{*}{$\begin{array}{c}\mathbf{R}^{2} \\
0.9923 \\
0.9337\end{array}$} & \multirow{3}{*}{\begin{tabular}{c}
\multicolumn{1}{c}{$\mathbf{a}$} \\
0.001 \\
0.0005
\end{tabular}} & \multirow{3}{*}{$\begin{array}{c}\mathbf{b} \\
0.0024 \\
0.0011\end{array}$} & \multirow{3}{*}{$\begin{array}{c}\mathbf{R}^{2} \\
0.9754 \\
0.8017\end{array}$} \\
\hline MSN- & pH 1.2 & & & & & & & & & & & \\
\hline $\mathrm{BZC}$ & $\mathrm{pH} 7.4$ & & & & & & & & & & & \\
\hline AL- & pH 1.2 & 98.81 & 0.00184 & 0.9796 & 0.2925 & 0.9456 & 0.4913 & 0.5 & 0.9594 & 0.0023 & 0.0067 & 0.9875 \\
\hline $\mathrm{BZC}$ & pH 7.4 & 90.78 & 0.00046 & 0.9681 & 0.1951 & 0.9976 & 0.9806 & 0.5379 & 0.9964 & 0.0017 & 0.0054 & 0.9466 \\
\hline CS- & $\mathrm{pH} 1.2$ & 83.69 & 0.00276 & 0.885 & 0.526 & 0.8266 & 0.1418 & 0.3782 & 0.94 & 0.0034 & 0.0079 & 0.9974 \\
\hline $\mathrm{BZC}$ & pH 7.4 & 96.74 & 0.00184 & 0.991 & 0.433 & 0.9442 & 0.2283 & 0.4401 & 0.9801 & 0.0031 & 0.0085 & 0.9845 \\
\hline \multirow{2}{*}{$\begin{array}{l}\text { AL- } \\
\text { MSN- } \\
\text { BZC } \\
\end{array}$} & pH 1.2 & 96.83 & 0.001152 & 0.9407 & 0.2026 & 0.9795 & 0.5025 & 0.45 & 0.9892 & 0.0016 & 0.0046 & 0.9736 \\
\hline & pH 7.4 & 96.6 & 0.00046 & 0.88 & 0.1684 & 0.8716 & 1.7196 & 0.5924 & 0.9559 & 0.0015 & 0.0055 & 0.7707 \\
\hline \multirow{2}{*}{$\begin{array}{l}\text { CS- } \\
\text { MSN- } \\
\text { BZC } \\
\end{array}$} & $\mathrm{pH} 1.2$ & 74.1 & 0.00069 & 0.8743 & 0.6255 & 0.8451 & 0.2614 & 0.4146 & 0.9304 & 0.0043 & 0.0106 & 0.9949 \\
\hline & pH 7.4 & 97.19 & $1.15 \times 10^{-9}$ & 0.977 & 0.9418 & 0.9555 & 3.8884 & 0.6314 & 0.9911 & 0.0098 & 0.0376 & 0.8927 \\
\hline
\end{tabular}

The release of BZC from polymer obeys the Weibull model in $\mathrm{pH} 1.2$ with a R2 values of 0.9974 for CS-BZC and 0.9875 for Al-BZC meaning that the properties of the release medium have a high impact on drug release. Al tends to be more stable at $\mathrm{pH} 1.2$ compared with $\mathrm{CS}$. At pH 7.4, the release of BZC obeys the first order or Higuchi model having a coefficient R2 value of 0.991 for CS-BZC and of 0.9681 for Al-BZC, meaning that the drug was transported from the matrix by diffusion for both CS and Al.

The introduction of MSN in the polymer matrix does not induce a significant modification in the release mechanism. At pH 1.2, the Weibull or Higuchi model describes the drug release and also the diffusion is the transport mechanism due to the different stability of the two polymers in SGF. Conversely, at pH 7.4 the mathematic model that describes the release mechanism is the first order model meaning that MSN induce its porosity in the hybrid material. The results obtained fit well the synthesized materials because the model is similar to a drug delivery system that contains watersoluble drugs which are encapsulated into porous matrices [33]. This time the drug respects the case II mechanism transport from the hybrid material (swelling followed by erosion).

\section{Conclusions}

The successful modification of MSN with different amounts of BZC was proved by FT-IR spectra in which distinctive bands assigned to BZC structure into the MSN-BZC spectra were identified, as well from the TGA data where a significant mass loss is obtained for MSN-BZC compared with pure MSN. Moreover, XPS was used to confirm the presence of BZC on the MSN surface.

The $\mathrm{pH}$ value of the environment, the contact time or the temperature used during the adsorption experiments proved to be important factors in the encapsulation process of BZC into the MSN. The highest encapsulation degree was recorded in solution having $\mathrm{pH}$ value of 5, at room temperature when the MSN was immersed for 60 min into the BZC containing solution. The adsorption process type as well as the adsorption rate, the kinetic parameters and thermodynamic parameters were determined.

Using a casting method, we obtained CS/AL-BZC and CS/AL-MSN-BZC composite films, which were further tested as potential drug delivery systems. The release profile of BZC from different 
systems, was studied in both SGF and SIF. The biopolymers are intended to increase the amount of the drug release by improving the dispersion of the MSN and allow a better diffusion of the drug. This is evident from the drug release curves of the MSN-BZC hybrid materials with and without the polymer. SEM proved the dispersion of the MSN within the polymer matrices whereby we observed a good distribution of the inorganic filler within the Al-MSN-BZC and the formation of some agglomeration in the case of CS-MSN-BZC. The dissolution media and the presence of MSN in the polymer matrix significantly influence the release mechanism. In SIF the release mechanism of BZC obeys the first order model because MSN increases the porosity of the hybrid materials.

Author Contributions: A.M.P. and C.A. were involved in laboratory experiments regarding the modification process and FT-IR, XPS and TGA characterization of the modified MSN. A.M.P. also performed the experimental protocol in order to study the influence of different parameters for the adsorption experiments. A.G. was involved in the calculation of the mathematic models including first-order, Higuchi, Korsmeyer-Peppas and Weibull of the release mechanism. S.A.G. is involved on synthesis of the hybrid materials and study of the in vitro drug release. H.I. is the mentor of this original idea and supervises the whole research work. All authors were involved in the results discussion, data interpretation and finalizing the manuscript.

Funding: The work has been funded by the Sectoral Operational Programme Human Resources Development 2007-2013 of the Ministry of European Funds through the Financial Agreement POSDRU/159/1.5/S/132397.

Conflicts of Interest: The authors declare no conflict of interest.

\section{References}

1. Digge, M.S.; Moon, R.S.; Gattani, S.G. Application of Carbon Nanotubes in Drug Delivery: A Review. Int. J. PharmTech Res. 2012, 4, 839-847.

2. Alhamdi, J.; Jacobs, E.; Gronowicz, G.; Benkirane-Jessel, N.; Hurley, M.; Kuhn, L. Cell Type Influences Local Delivery of Biomolecules from a Bioinspired Apatite Drug Delivery System. Materials 2018, 11, 1703. [CrossRef] [PubMed]

3. Bernkop-Schnürch, A. Nanocarrier systems for oral drug delivery: Do we really need them? Eur. J. Pharm. Sci. 2013, 49, 272-277. [CrossRef] [PubMed]

4. Vallet-Regí, M.; Rámila, A.; del Real, P.R.; Pérez-Pariente, J. A New Property of MCM-41: Drug Delivery System. Chem. Mater. 2001, 13, 308-311. [CrossRef]

5. Zhao, Y.Z.; Sun, C.Z.; Lu, C.T.; Dai, D.D.; Lv, H.F.; Wu, Y.; Wan, C.W.; Chen, L.J.; Lin, M.; Li, X.K. Characterization and anti-tumor activity of chemical conjugation of doxorubicin in polymeric micelles (DOX-P) in vitro. Cancer Lett. 2011, 311, 187-194. [CrossRef] [PubMed]

6. Marcelo, G.; Ariana-Machado, J.; Enea, M.; Carmo, H.; Rodriguez-Gonzales, B.; Capelo, J.L.; Lodeiro, C.; Oliviera, E. Toxicological Evaluation of Luminescent Silica Nanoparticles as New Drug Nanocarriers in Different Cancer Cell Lines. Materials 2018, 11, 1310. [CrossRef] [PubMed]

7. Miculescu, F.; Mocanu, A.C.; Dascalu, C.A.; Maidaniuc, A.; Batalu, D.; Berbecaru, A.; Voicu, S.I.; Miculescu, M.; Thakur, V.K.; Ciocan, L.T. Facile synthesis and characterization of hydroxyapatite particles for high value nanocomposites and biomaterials. Vacuum 2017, 146, 614-622. [CrossRef]

8. Chen, J.; Xia, N.; Zhou, T.; Tan, S.; Jiang, F. Mesoporous carbon spheres: Synthesis, characterization and supercapacitance. Int. J. Electrochem. Sci. 2009, 4, 1063-1073.

9. Vallet-Regi, M.; Balas, F.; Arcos, D. Mesoporous materials for drug delivery. Chem. Mater. 2007, 46, 7548-7558. [CrossRef]

10. Swatantra, K.K.S.; Awani, R.K.; Satyawan, S. Chitosan: A Platform for Targeted Drug Delivery. Int. J. PharmTech Res. 2010, 2, 2271-2282.

11. Tonnesen, H.H.; Karlsen, J. Alginate in drug delivery systems. Drug Dev. Ind. Pharm. 2002, 28, 621-630. [CrossRef] [PubMed]

12. Farías, T.; Charles de Ménorval, L. Benzalkonium chloride and sulfamethoxazole adsorption onto natural clinoptilolite: Effect of time, ionic strength, $\mathrm{pH}$ and temperature. J. Colloid Interface Sci. 2011, 363, 465-475. [CrossRef] [PubMed]

13. Kostić, D.A.; Mitić, S.S.; Nasković, D.C.; Zarubica, A.R.; Mitic, M.N. Determination of Benzalkonium Chloride in Nasal Drops by High-Performance Liquid Chromatography. E-J. Chem. 2012, 9, 1599-1604. [CrossRef] 
14. Ghebaur, A.; Garea, S.A.; Iovu, H. New polymer-halloysite hybrid materials-Potential controlled drug release system. Int. J. Pharm. 2012, 436, 568-573. [CrossRef] [PubMed]

15. Mhlanga, N.; Ray, S.S. Kinetic model for the release of the anticancer drug doxorubicin from biodegradable polylactide/metal oxide- based hybrid. Int. J. Biol. Macromol. 2015, 72, 1301-1307. [CrossRef] [PubMed]

16. Petropoulous, J.H.; Papadokostaki, K.G.; Sanopoulou, M. Higuchi's equations and beyond: Overview of the formulation and application of generalized model of drug release from polymeric matrices. Int. J. Pharm. 2012, 437, 178-191. [CrossRef]

17. Bruschi, M. (Ed.) Mathematical models of drug release. In Strategies to Modify the Drug Release from Pharmaceutical Systems; Woodhead Publishing: Cambridge, UK, 2015; pp. 63-86.

18. Jose, S.; Fangueiro, J.F.; Smitha, J.; Cinu, T.A.; Chacko, A.J.; Premaletha, K.; Souto, E.B. Predictive modeling of insulin release profile from cross-linked chitosan microspheres. Eur. J. Med. Chem. 2013, 60, 249-253. [CrossRef]

19. Lungan, M.A.; Popa, M.; Racovita, S.; Hitruc, G.; Doroftei, F.; Desbieres, J.; Vasiliu, S. Surface characterization and drug release from porous microparticles based on methacrylic monomers and xanthan. Carbohydr. Polym. 2015, 125, 323-333. [CrossRef]

20. Korsmeyer, R.W.; Gurny, R.; Doelker, E.; Buri, P.; Peppas, N.A. Mechanisms of solute release from porous hydrophilic polymers. Int. J. Pharm. 1983, 15, 25-35. [CrossRef]

21. Tang, J.; Slowing, I.I.; Huang, Y.; Trewyn, B.G.; Hu, J.; Liu, H.; Lin, V.S.Y. poly(lactic acid)-coated mesoporous silica nanosphere for controlled release of venlafaxine. J. Colloid Interface Sci. 2011, 360, 488-496. [CrossRef]

22. Li, Z.; Su, K.; Cheng, B.; Deng, Y. Organically modified MCM-type material preparation and its usage in controlled amoxicillin delivery. J. Colloid Interface Sci. 2010, 342, 607-613. [CrossRef]

23. Havasi, F.; Ghorbani-Choghamarani, A.; Nikpour, F. Pd-Grafted functionalized mesoporous MCM-41: A novel, green and heterogeneous nanocatalyst for the selective synthesis of phenols and anilines from aryl halides in water. New J. Chem. 2015, 39, 6504-6512. [CrossRef]

24. Najafi, M.; Yousefi, Y.; Rafati, A.A. Synthesis, characterization and adsorption studies of several heavy metal ions on amino-functionalized silica nano hollow sphere and silica gel. Sep. Purif. Technol. 2012, 85, 193-205. [CrossRef]

25. Bui, T.X.; Choi, H. Adsorptive removal of selected pharmaceuticals by mesoporous silica SBA-15. J. Hazard. Mater. 2009, 168, 602-608. [CrossRef]

26. Huang, C.H.; Chang, K.P.; Ou, H.D.; Chiang, Y.C.; Wang, C.F. Adsorption of cationic dyes onto mesoporous silica. Microporous Mesoporous Mater. 2011, 141, 102-109. [CrossRef]

27. Kuo, C.Y. Comparison with as-grown and microwave modified carbon nanotubes to removal aqueous bisphenol A. Desalination 2009, 249, 976-982. [CrossRef]

28. Mohammadi, N.; Khani, H.; Gupta, V.K.; Amereh, E.; Agarwal, S. Adsorption process of methyl orange dye onto mesoporous carbon material-kinetic and thermodynamic studies. J. Colloid Interface Sci. 2011, 362, 457-462. [CrossRef]

29. Zanini, G.P.; Ovesen, R.G.; Hansen, H.C.B.; Strobel, B.W. Adsorption of the disinfectant benzalkonium chloride on montmorillonite. Syntergetic effect in mixture of molecules with different chain lengths. J. Environ. Manag. 2013, 128, 100-105. [CrossRef]

30. Huang, X.; Xiao, Y.; Lang, M. Micelles/sodium-alginate composite gel beads: A new matrix for oral drugdelivery of indomethacin. Carbohydr. Polym. 2012, 87, 790-798. [CrossRef]

31. Miculescu, F.; Bojin, D.; Ciocan, L.T.; Antoniac, I.A.; Miculescu, M.; Niculescu, N. Experimental Research on Biomaterial-Tissue Interface Interactions. J. Optoelectron. Adv. Mater. 2007, 9, 3303-3306.

32. Martin, A.; Morales, V.; Ortiz-Bustos, J.; Perez-Garnes, J.; Bautista, L.F.; Garcia-Munoz, R.A.; Sanz, R. Modelling the adsorption and controlled release of drug from the pure and amino surface-functionalized mesoporous silica host. Microporous Mesoporous Mater. 2018, 262, 23-34. [CrossRef]

33. Dash, S.; Murthy, P.N.; Nath, L.; Chowdhury, P. Kinetic modeling on drug release from controlled drug delivery systems. Acta Pol. Pharm. 2010, 67, 217-223. [PubMed]

(C) 2018 by the authors. Licensee MDPI, Basel, Switzerland. This article is an open access article distributed under the terms and conditions of the Creative Commons Attribution (CC BY) license (http:/ / creativecommons.org/licenses/by/4.0/). 